\title{
$O$ ato enunciativo e a instauração da experiência de trabalho de profissionais de enfermagem
}

\author{
The enunciative act and the establishment of nursing work experience
}

\author{
Marlene TEIXEIRA* \\ Universidade do Vale do Rio dos Sinos (UNISINOS/CNPq)
}

\begin{abstract}
RESUMO: Este texto tem por objetivo apresentar a interlocução entre os saberes da teoria enunciativa da linguagem (Émile Benveniste) e da perspectiva ergológica (Yves Schwartz) como fundamento para o estudo da instauração da experiência de trabalho de profissionais de enfermagem, tomando como locus de observação passagens de plantão no cotidiano de um hospital. Para tanto, propõe a extensão do escopo das formulações de Benveniste para além dos domínios da linguística, na direção de uma ciência geral do homem. Ilustra essa proposição com o estudo dos pronomes desenvolvido pelo autor, que os descreve como categorias que dão a ver a dialética singular pela qual o locutor acessa a língua e na qual vemos a experiência subjetiva se instaurar.
\end{abstract}

PALAVRAS-CHAVE: Enunciação. Subjetividade. Quadro figurativo. Ergologia. Atividade de trabalho.

ABSTRACT: The purpose of this paper is to present a dialogue between the enunciation theory of language (Émile Benveniste) and the ergological viewpoint (Yves Schwartz) as a foundation for studying the establishment of the nursing work experience, with a focus on observing nursing shift changes in the daily activities of a hospital. To this end, we propose broadening the scope of formulations by Benveniste beyond the domain of linguistics towards a general human science. This proposal is illustrated by the study on pronouns developed by the author, which describes them as categories that reveal the singular dialectic through which the speaker accesses language and in which we can see the subjective experience become established.

KEYWORDS: Enunciation. Subjectivity. Figurative Framework. Ergology. Work activity.

\section{Introdução}

Émile Benveniste ensina que a experiência humana não precede cronologicamente a linguagem; ela é contemporânea à enunciação, produzindo, a cada vez, o homem como sujeito. É, pois, no ato de apropriação da língua pelo locutor que a experiência advém, numa relação indissociável com a (inter)subjetividade. Sob essa ótica, os protagonistas da linguagem (eu-tu) não podem ser considerados processadores automáticos ou computadores biológicos mais ou menos programados para lidar com um código linguístico que lhes é exterior; o uso da linguagem está ligado a uma forma de vida. Parece estar no projeto de Benveniste a expressão da necessidade de desenvolver uma teoria que não só descreva a língua-discurso do ponto de vista de seu funcionamento enunciativo, mas que possibilite produzir conhecimento sobre o homem.

\footnotetext{
* Doutorado em Linguística; bolsista de Produtividade em Pesquisa (CNPq) e professora da Universidade do Vale do Rio dos Sinos (UNISINOS), Curso de Letras, Programa de Pós-Graduação em Linguística Aplicada e Mestrado Profissional em Enfermagem. São Leopoldo - RS - Brasil. E-mail: martei.poa@gmail.com.
} 
É esse o viés que orienta minha leitura de Benveniste, isto é, a meu ver, embora não deixe de estar inscrita no campo da linguística, sua teoria enunciativa transborda para o âmbito das relações entre a linguagem e o homem. Sob essa hipótese, venho buscando desenvolver, em interface com a ergologia ${ }^{1}$, estudos sobre as condições enunciativas de instauração da experiência de trabalho na área da saúde, mediante o acompanhamento de profissionais em seus espaços naturais de trabalho, registrando e analisando suas manifestações de linguagem, sempre particulares a cada grupo, a cada instituição, a cada ato de enunciação. Nesses estudos, o recurso à análise enunciativa da linguagem é proposto não para descrever a língua por si só, mas como uma forma de contribuir para compreender questões de natureza mais ampla.

A ergologia é uma perspectiva pluridisciplinar inovadora, que permite abordar a complexidade intrínseca da atividade humana. Teve início nos primórdios dos anos 1980, principalmente, na Université de Provence, sob o pressuposto de que a atividade industriosa humana não pode jamais ser totalmente antecipada por nenhum modelo teórico, constituindo-se como uma realidade complexa, que sempre comporta uma parte invisível provisória, na espera de uma eventual elucidação, e uma parte irredutivelmente enigmática (SCHWARTZ, 2011). Durante seu percurso, foi progressivamente enriquecida por colaborações científicas, por projetos cooperativos de diversas disciplinas, não só na França, mas também em países como Brasil, Portugal, Argélia, entre outros.

Segundo a perspectiva ergológica, a atividade humana não pode, sem redução, ser simplesmente assimilada a comportamentos observáveis; ela é definida pela dimensão simbólica. Assim, a linguagem aí ocupa um lugar central. Não é de estranhar que a competência disciplinar do linguista seja solicitada para integrar a reflexão sobre a atividade de trabalho. Os estudos ergológicos entendem que na passagem entre o dizer e 0 fazer intervém uma entidade enigmática (o corpo-si), que compreende a inteligência, o sistema nervoso, a história e, também, o inconsciente de « tipo psicanalítico », que age em nossa vida de trabalho como age em nossa vida geral (SCHWARTZ; DURRIVE, 2010, p. 146).

Desse modo, soa natural o diálogo da ergologia com a teoria enunciativa de Benveniste, que descreve a linguagem em relação à singularidade do uso feito por um locutor em uma situação dada, supondo que a conversão da língua em discurso só é possível por um ato que implica o sujeito, o que significa compreender que a entrada do homem na língua a transforma radicalmente.

Este texto tem por objetivo fazer operar esses saberes para entender melhor a instauração da experiência de trabalho de profissionais de enfermagem, tomando como locus de observação passagens de plantão no cotidiano de um hospital. Em primeiro lugar, discute-se que, pela natureza dos saberes da enunciação e da ergologia, o diálogo entre ambos institui-se sob uma outra racionalidade, não mais orientada por conceitos abstratos, formulados à revelia do aqui-e-agora, mas capaz de suportar a intervenção da matéria complexa de que é feita a atividade, impossível de ser capturada na forma de um saber positivo totalizante. A seguir, são brevemente desenvolvidos os conceitos de Benveniste e Schwartz que fundamentam a análise dos recortes selecionados ${ }^{2}$ para ilustrar o tipo de contribuição que a linguística da enunciação pode trazer à compreensão da complexa alquimia humana que se dá na experiência de trabalho no campo da enfermagem.

\footnotetext{
${ }^{1}$ A palavra ergologia se origina do verbo grego ergasesthai, e pode ser entendida como investigações sobre a atividade humana (SCHWARTZ, 2012). Particularmente, recorro a formulações de Yves Schwartz.

${ }^{2}$ Os recortes que serão analisados constituem o corpus da pesquisa A linguística da enunciação e o campo aplicado: um estudo da subjetividade na atividade do profissional de enfermagem (Processo PQ - CNPq 305608/2009-6), desenvolvida junto ao Programa de Pós-Graduação em Linguística Aplicada da UNISINOS.
} 


\title{
1 Em busca de uma ciência que sirva para viver
}

Em sua reflexão sobre a nova ordem de produção do conhecimento que se desenha hoje, em razão da crise da ordem científica hegemônica, Boaventura S. Santos (2002, p. 53-54) faz uma observação bastante instigante para quem quer que transite, de algum modo, pela seara acadêmica:

\begin{abstract}
A ciência moderna legou-nos um conhecimento funcional do mundo que alargou extraordinariamente as nossas perspectivas de sobrevivência. Hoje não se trata tanto de sobreviver como de saber viver. Para isso é necessária uma outra forma de conhecimento, um conhecimento compreensivo e íntimo que não nos separe e antes nos una pessoalmente ao que estudamos (SANTOS, 2002, p. 53-54).
\end{abstract}

A questão que ele traz faz pensar nos destinos da linguística nesse novo desenho da ciência no século XXI. Nascida a partir da preocupação em ser tão científica quanto as ciências reconhecidas como "autênticas", a linguística, por um longo tempo, ocupou-se em desenvolver métodos científicos próprios, a partir de concepções rigorosas e de aceitação universal. A cientifização da linguística fez-se pela idealização do objeto, isto é, pela abstração de aspectos que não podem ser tratados com a precisão, a profundidade e o rigor dos modelos de racionalidade das ciências naturais clássicas que orientam o paradigma dominante.

A necessidade de superar a parcialização do conhecimento promovida pela redução da complexidade do objeto de estudo fez surgir, a partir de meados do século XX, inúmeras disciplinas dentro da linguística ${ }^{3}$ para atender a aspectos da linguagem eliminados dos estudos iniciais.

Os formalismos produziram resultados consideráveis no que diz respeito à compreensão dos princípios que regem o sistema, ao desenvolvimento de modelos de base lógica e matemática para explicar a linguagem. Por sua vez, as diferentes linguísticas trazem contribuições extraordinárias para o conhecimento de aspectos sócio-cognitivofuncionais da linguagem em uso. Esse conjunto de estudos tem o mérito de conquistar para a linguística um lugar de prestígio no campo da ciência.

Num e noutro caso, no entanto, a preocupação com a delimitação de fronteiras é forte, a produção de conhecimento, estanque e a aplicação desse conhecimento, ainda bastante restrita a situações de ensino de língua.

Voltando ao excerto retirado de Santos (2002, p. 53-54), com que iniciei este item, pode-se dizer que os linguistas, de um modo geral, quase não têm se integrado ao movimento de produção dessas outras formas de conhecimento de que fala o filósofo português. Para a ciência que se movimenta na direção do "saber viver", o conhecimento necessário não é tanto explicativo e genérico, mas "compreensivo e íntimo" (SANTOS, 2002, p. 53); não promove a dissociação sujeito/objeto, mas reconhece as implicações da interferência estrutural do sujeito no objeto observado; não descarta o senso comum, mas o reabilita, por reconhecer nessa forma de conhecimento virtualidades capazes de "enriquecer nossa relação com o mundo" (SANTOS, 2002, p. 56); não promove a redução do objeto, mas procede pela "diferenciação e pelo alastramento das raízes em busca de novas e mais variadas interfaces” (SANTOS, 2002, p. 48). Aqueles que quiserem atender essa demanda precisam aceitar o desafio de retirar os estudos linguísticos de seu isolamento disciplinar, tornando seu capital conceitual menos nebuloso, não só para o contexto acadêmico, mas, sobretudo, para a sociedade.

\footnotetext{
${ }^{3}$ Sociolinguística, psicolinguística, linguística do texto, entre outras.
} 
Fazer convergir os saberes da enunciação e da ergologia é um esforço nessa direção. Essa convergência interdisciplinar visa à produção de conhecimento sobre o trabalho vivo, por meio da análise do ato enunciativo que instaura a experiência profissional, a partir da hipótese de que a teoria da enunciação de Benveniste é um lugar em que o saber conceptual sobre a linguagem se encontra estreitamente ligado à situação vivida aqui-e-agora, podendo, por essa razão, dialogar com o saber da ergologia na análise da atividade de trabalho. Como ambos os saberes estão alinhados com o movimento de fazer da ciência um encontro com a pulsação da vida, tomá-los como base implica entregar-se a um exercício de pensamento que procura produzir conhecimento sem neutralizar as condições singulares ligadas ao tempo e ao lugar em que ocorre a atividade de trabalho.

Para levar adiante a proposta, parece-me indispensável definir uma nova configuração para integrar os diferentes conceitos científicos mobilizados nesses campos do conhecimento. Nessa tentativa, recorro a contribuições recentes de Schwartz à epistemologia, que instauram "uma nova maneira de abordar a questão das disciplinas e dos conceitos” (SOUZA-e-SILVA; MOTTA, 2012).

Schwartz $^{4}$ divide as disciplinas em dois campos, conforme seus objetos forem sem ou com debate de normas ${ }^{5}$ : o campo epistêmico e o campo ergológico. O campo epistêmico reúne disciplinas cujos objetos não têm debate de normas (por exemplo, uma reação química). Corresponde à exigência de trabalho com conceitos, que visa "construilos, precisá-los, complexificá-los, libertando-os da aderência local e dos valores que aí são retrabalhados” (DURRIVE; SCHWARTZ, 2008, p. 25). O campo ergológico está sujeito à atividade, e não pode ser estudado fora do meio e da história. Por essa razão, as disciplinas desse campo constituem-se em espaços de debate de normas, em que a construção de saberes conjuga, ao mesmo tempo, o polo dos conceitos e o trabalho vivo.

Diferentes níveis de epistemicidade caracterizam o saber conceptual, de acordo com Schwartz: a epistemicidade 1 se manifesta no seio do campo epistêmico (ciências ditas “duras”) para produzir conhecimento, através de conceitos, leis e modelos, sobre objetos que não têm debate de normas (por exemplo, a lei da queda dos corpos); as epistemicidades de níveis 2, 3 e 3 bis remetem ao campo ergológico cujos objetos estão submetidos a debates de normas. A epistemicidade 2 conhece uma relativa estabilidade, pois caracteriza a produção de normas no seio da vida social, cristalizadas em conceitos, leis, regulações e procedimentos (por exemplo, o contrato de trabalho). A epistemicidade 3 remete a conceitos elaborados no quadro das disciplinas humanas e sociais (por exemplo, as teorias de gestão). No nível 3 a estabilidade é ainda mais relativa e há risco de usurpação conceptual ${ }^{6}$ sempre que se pretender fazer um uso totalizante dos conceitos operacionalizados. A epistemicidade 3 bis remete a uma conceptualização própria à perspectiva ergológica de análise das situações de trabalho, operacionalizando conceitos que compreendem a variabilidade dos objetos que eles designam, isto é, que produzem

\footnotetext{
${ }^{4}$ Cf. exposição oral feita no minicurso ministrado pelo filósofo Yves Schwartz no LAEL (PUC/SP) em abril de 2012.

${ }^{5}$ Segundo Schwartz, a atividade humana decorre de uma dialética entre normas que antecipam o fazer e renormalizações decorrentes das arbitragens inerentes ao agir. Nesse sentido, a atividade se constitui por um debate entre o que está estabilizado e o que é da ordem do vivido na situação, de que inevitavelmente resulta uma modificação no estado das coisas. No terreno da ciência, o debate que se trava é entre o saber acadêmico previamente instituído e o saber investido, resultante da atividade humana.

${ }^{6}$ Categorizar, julgar, avaliar as atividades humanas de acordo com protocolos e procedimentos que imitam as ciências naturais e matemáticas é o que, segundo Schwartz (2012), se pode chamar usurpação. A usurpação ocorre, então, quando se olha para o humano, colocando entre parênteses as dimensões históricas do meio e do momento.
} 
conhecimento sem neutralizar as condições singulares ligadas ao aqui-e-agora em que se dá a atividade humana. ${ }^{7}$

O campo epistêmico produz conhecimento em desaderência com a realidade concreta. Já o campo ergológico, que inclui as epistemicidades 2, 3 e 3 bis, aspira a construir conceitos que, como todo conceito, ambicionam pertencer à esfera da desaderência, mas, particularmente no nível 3, são obrigados a se defrontar com as renormalizações decorrentes das situações humanas vividas no momento presente. Embora a linguagem científica, no seu uso padronizado, tenha necessidade de fazer com que as realidades sejam relativamente estáveis, e por isso recorre à formulação de conceitos em desaderência, a atividade ultrapassa o que pode ser antecipado pela dimensão conceitual, pois, na sua origem, tem lugar um "drama” - individual ou coletivo - que "quebra o ritmo" das sequências habituais da vida (DURRIVE; SCHWARTZ, 2008, p. 25).

Uma dupla confrontação está implicada no fazer científico que diz respeito à atividade: confrontação de conceitos em desaderência; confrontação dos saberes em aderência com a experiência humana. Assim, no que diz respeito às ciências do homem, Schwartz propõe um modo de construção de saberes em que a desaderência conceptual seja permanentemente submetida à aderência do viver. Operar com a atividade humana, na perspectiva ergológica, coloca, então, o fazer científico diante de uma dupla racionalidade: (a) aquela orientada pelos saberes abstratos (em desaderência); (b) aquela orientada pela atividade (em aderência local).

Desse modo, a pesquisa que toma por objeto a atividade de trabalho não tem como deixar de enfrentar o desconforto teórico-metodológico provocado pelo que advém do aqui-e-agora da experiência, ou seja, o desconforto intelectual é parte constitutiva do método ergológico.

Se os especialistas do conceito tendem a buscar conforto na "torre de marfim da racionalidade intelectual” (DURRIVE; SCHWARTZ, 2008, p. 24), satisfazendo-se com modelos concebidos em desaderência total com a atividade, o campo ergológico, ao contrário, coloca o pesquisador na situação de ter que "suportar" a situação incômoda de reconhecer os limites dos conceitos científicos diante da realidade que eles visam explicar. A expressão "desconforto intelectual” designa exatamente essa postura diretamente ligada à concepção ergológica da atividade, que não deixa o estudioso se instalar em "interpretações estabilizadas dos processos e dos valores em jogo numa situação de atividade” (DURRIVE; SCHWARTZ, 2008, p. 24-5).

A teoria enunciativa de Benveniste se coloca como um saber sobre a linguagem que pode reivindicar lugar no campo ergológico de produção do conhecimento, incluindo-se no nível de epistemicidade 3 bis, pois, sem deixar de lado o âmbito abstrato, acolhe em seu objeto o ato sempre singular pelo qual o sujeito advém na e pela enunciação. Em outras palavras, no processo de estudo da linguagem, Benveniste aproxima os conceitos com os quais opera do que a ergologia chama de aderência local (DURRIVE; SCHWARTZ, 2008, p. 23), ou seja, da situação vivida aqui e agora. Sem deixar de lado conceitos construídos em desaderência, isto é, neutros em relação ao aqui-e-agora, $r e^{8}$-formula-os de modo a torná-los aptos a "surpreender" a intervenção da subjetividade em situações de uso da

\footnotetext{
${ }^{7}$ Sobre a questão das epistemicidades, ver o livreto que acompanha o DVD: SCHWARTZ, Y. La démarche ergologique. Cours donnés par Y. SCHWARTZ à l'invitation de la chaire de la formation des adultes du CNAM de Paris pour le máster "Développement des Compétences et Intervention dans les organisations". DVD, diffusion ORT, 2008. Ver também o item 3.3.1 em: MAILLIOT, S. Penser les processus de changement à travers l'expérience de la mobilité professionnelle, de l'objet discursif à l'activité de transition. Thèse de doctorat. Aix - Marseille Université, 2012.

${ }^{8}$ O prefixo re- tem um valor crítico na teoria de Benveniste. Segundo Dessons (2006), esse prefixo apresenta dois sentidos nos textos benvenistianos: de iteração e de invenção. A esse respeito, consultar também Juchem (2012).
} 
linguagem. O linguista que trabalha sob essa perspectiva deixa o terreno "seguro" de estudo das regularidades para defrontar-se com uma "matéria estranha", que o destitui do lugar de poder dominar inteiramente seu objeto.

A expressão "matéria estranha” é utilizada por G. Canguilhem (2007, p. 6) em reflexão sobre a natureza da matéria de que se deve ocupar o filósofo: "A filosofia é uma reflexão para a qual qualquer matéria estranha serve, ou diríamos mesmo para a qual só serve a matéria que lhe for estranha”.

É a esse autor que Schwartz (2008) se refere em texto que reflete sobre a constituição da atividade de trabalho do ponto de vista filosófico. Para ele (2008, p. 25-26), a filosofia só poderá contribuir para entender e transformar o trabalho, se levar em conta que a atividade humana comporta uma "matéria estranha", não se deixando aprisionar por categorias e definições estanques.

Tomo a noção de "matéria estranha" de um modo particular, entendendo-a como o conjunto de aspectos que as ciências humanas procuram neutralizar de qualquer relação com o aqui-e-agora. Trata-se do saber que exorbita o objeto tal como é constituído dentro da visão hegemônica de ciência. Para integrar os diferentes conceitos científicos mobilizados em minha proposta, a noção de "matéria estranha" é considerada como operadora da interlocução interdisciplinar entre as áreas da enunciação e da ergologia.

Neste item, procurei esclarecer a natureza da interlocução proposta para a análise da atividade de trabalho de profissionais de enfermagem. A seguir, apresento o ponto de vista em que sustento a re-leitura da teoria enunciativa de Benveniste.

\title{
2 Por onde a teoria enunciativa de Benveniste encontra a experiência humana
}

A ampliação do escopo da teoria de Benveniste para além dos estudos linguísticos stricto sensu que aqui é proposta sustenta-se em um princípio derivado das palavras com que o autor inicia sua reflexão sobre a linguagem e a experiência humana, em texto de 1965 (citado em PLGII, 1989, p. 68), que assim pode ser formulado: a experiência subjetiva se coloca e se situa na e pela linguagem.

A validação desse princípio pode ser feita com base em formulações do autor sobre os pronomes, por serem essas as formas linguísticas que mais prontamente dão a ver que é na e pela enunciação que a experiência humana se instaura. ${ }^{9}$ Esse estudo é apresentado ao longo de vários textos, nos dois volumes de Problemas de Linguística Geral ${ }^{10}$ (1988, 1989).

O próprio Benveniste dá testemunho de que sua descrição dos pronomes transcende o âmbito puramente linguístico, em seus artigos clássicos sobre esse tema, como se pode perceber no excerto abaixo:

\begin{abstract}
Todas as línguas têm em comum certas categorias de expressão que parecem corresponder a um modelo constante. As formas que revestem essas categorias são registradas e inventoriadas nas descrições, mas suas funções não aparecem claramente senão quando se estuda no exercício da língua e na produção do discurso. São categorias elementares, independentes de toda determinação cultural e nas quais vemos a experiência subjetiva dos sujeitos que se colocam e se situam na e pela linguagem. (PLG II, 1989, p. 68)
\end{abstract}

\footnotetext{
${ }^{9}$ Com isso, não se está desconhecendo que a língua toda como implicada no ato de instauração da experiência humana.

${ }^{10}$ Doravante, PLG I e PLG II.
} 
O traço universal da categoria de pessoa e sua relação com a instauração da experiência humana tem sido fonte de inspiração para reflexões significativas de estudiosos de diferentes áreas, desde os anos 1960 até a atualidade. Destacam-se as incursões nessa direção feitas no campo da literatura (cf. BARTHES, 1988); da antropologia (cf. CASTRO, 1996); da filosofia (cf. DUFOUR, 2000 e AMGABEN, 2008). A referência feita a Benveniste nesses trabalhos demonstra que, mais do que uma descrição de categorias fundamentais da língua, seu estudo sobre os pronomes coloca-nos no âmago de uma problemática da interlocução, pois essas categorias são precisamente aquelas em que se amarram as relações do eu com aquilo que é privado da marca do eu. E, mais do que isso, coloca em evidência a relação radical da linguagem com o homem (TEIXEIRA, 2012a; 2012b). Enfim, a repercussão do estudo de Benveniste sobre os pronomes fora do âmbito da linguística explica-se pelo fato de ele dar a ver a dialética singular pela qual o locutor acessa a língua como uma "experiência central da qual se determina a possibilidade mesma do discurso” (BENVENISTE, PLG II, 1989, p. 69).

A linguagem é definida por Benveniste na estrita relação com o humano, assim como o humano é definido na estrita relação com a linguagem, como se pode constatar em sua célebre afirmação: "É na linguagem e pela linguagem que o homem se constitui como sujeito" (BENVENISTE, PLG I, 1988, p. 286). Além disso, ele a retira da condição de mero instrumento, "utilitário ou decorativo do pensamento" (BARTHES, 1988, p. 31), contrapondo-se ao lugar comum filosófico que define o homem por sua capacidade de comunicar. ${ }^{11}$ A linguagem, segundo Benveniste, "serve para viver", bem antes de servir para comunicar (BENVENISTE, PLG II, 1989, p. 222), ou seja, ela é entendida como fenômeno profundamente ancorado na experiência humana.

Vemos aí por onde o pensamento de Benveniste ultrapassa os limites da linguística para ligar-se a uma teoria geral da linguagem. Isso também é visível na entrevista a Dumur, no ponto em que Benveniste (PLG II, 1989) admite que, na elaboração de seu estudo, faz uso "do desenvolvimento de todas as ciências que seguem a mesma direção" (PLG II, p. 39); ou quando ele define a linguística como uma epistemologia (p. 38); ou ainda quando afirma seu interesse pela convergência entre várias ciências (p. 39). Nesse raciocínio, ele não deixa de destacar que a linguística pode ser útil para outros campos de estudo. Passar por ela, segundo o autor, “dá ao espírito uma certa formação”, permite-lhe tomar uma certa distância. Na sua visão, os estudos linguísticos interessam, sobretudo, por destruírem ilusões sobre o valor absoluto da língua, sobre os valores absolutos que cada um encontra em sua própria língua em relação a outras (p. 40). ${ }^{12}$

Em Benveniste, encontra-se, então, uma perspectiva nova de estudo da linguagem, que, num primeiro momento, foi identificada apenas como a possibilidade de descrever, na língua / na linguagem, as marcas da subjetividade, mas que assume um outro estatuto, com muito ainda a ser desvelado.

Situado o lugar em que coloco a teoria de Benveniste, apresento uma interpretação para a noção de enunciação, visando esclarecer o que estou chamando de condições enunciativas de instauração da experiência de trabalho.

\section{Por uma visão trinitária da enunciação}

A noção de enunciação varia muito ao longo dos textos de Benveniste. A. Ono (2007), em análise cronológica dos empregos dessa palavra na obra do autor, encontra perto de trinta ocorrências, nem todas com o mesmo sentido.

${ }^{11}$ Ele também contraria concepções idealistas do sujeito, bem como concepções representacionistas da relação entre a linguagem e o mundo.

${ }^{12}$ Conforme Teixeira (2012a). 
Se ficarmos só em $O$ aparelho formal da enunciação (PLG II), poderemos distinguir, segundo Ono (2007, p. 31-33), cinco modos pelos quais se pode entender o termo enunciação. Nesse texto, Benveniste dá uma ideia global do fenômeno enunciativo qualificando-o de "grande processo [que] pode ser estudado sob diversos aspectos". Ele distingue a esse propósito três eixos (PLG II, p. 82-84): (a) a realização vocal da língua; (b) a semantização da língua em discurso; (c) a realização individual da língua, considerada no quadro formal.

Segundo Ono, desses aspectos podem ser derivadas cinco particularidades essenciais da enunciação, que resumo a seguir:

1. A enunciação é uma "realização vocal da língua” (BENVENISTE, PLG II, 1989, p. 82).

2. A enunciação é um ato operacional que converte a língua em discurso.

3. A enunciação, enquanto realização individual, é um processo de apropriação da língua pelo locutor (PLG II, p. 84).

4. Toda enunciação é, "explícita ou implicitamente, uma alocução” (PLG II, p. 84).

5. Toda enunciação, mesmo fantástica e imaginária, liga o interlocutor ao mundo, ou mais precisamente, à realidade do discurso; a referência é parte da enunciação (PLG II, p. 84).

Para os propósitos deste estudo, tomo a enunciação como ato pelo qual o locutor se apropria da língua, num processo dialógico, para instaurar, uma experiência singular no tempo/espaço fugaz do aqui-e-agora. A língua toda, em Benveniste, pode ser estudada sob o ponto de vista da enunciação, o que confere a essa noção, que não se confunde nem com a de enunciado nem com a simples constatação da presença da subjetividade na linguagem, um papel determinante no empreendimento em direção a uma ciência geral do homem.

De acordo com esse entendimento do termo, observar a instauração de uma dada experiência requer que se leve em conta, antes de mais nada, o "quadro figurativo" da enunciação, estabelecido toda vez que, numa situação específica, os interlocutores assumem a língua. De acordo com Benveniste, em O aparelho formal da enunciação:

Como forma de discurso, a enunciação coloca duas 'figuras' igualmente necessárias, uma origem, a outra, fim da enunciação. Duas figuras na posição de parceiros são alternativamente protagonistas da enunciação. Este quadro é dado necessariamente com a definição de enunciação (PLG II, 1989, p. 87).

É pelo ato de enunciação, sempre renovado, que o locutor se apropria da língua para enunciar sua posição de sujeito, sujeito que, no dizer de Barthes (1988, p. 183), não é anterior à língua, pois só se torna sujeito na medida em que fala.

Por conceber o sujeito como contemporâneo da enunciação, a teoria de Benveniste não autoriza a vê-lo como efeito de permanência ligado ao emprego repetido do $e u$. Em $D a$ subjetividade na linguagem (BENVENISTE, PLG I, 1988), está claramente colocado que a "subjetividade" marca a passagem de locutor - noção que designa o indivíduo engajado em um processo de locução - a "sujeito”, processo que se dá na e pela linguagem. ${ }^{13}$

Essas observações permitem concluir que, pela apropriação do aparelho formal da língua, o locutor se instancia em seu discurso, dispondo, para isso, de indicadores de

13 Dessons (2006) destaca que confundir o locutor (sujeito enunciador) com o sujeito da enunciação é psicologizar o sujeito da enunciação. Segundo o autor, ao colocar a subjetividade no exercício da linguagem, a teoria de Benveniste define uma concepção de sujeito distinta do indivíduo locutor e se constituindo através de seu ato de fala. 
subjetividade. Mas o “colocar a língua em funcionamento” requer "encadeamentos de palavras", isto é, está ligado a uma sintaxe, que promove uma relação específica entre forma e sentido. Concordando com Flores (2012), consideramos que o sujeito advém como efeito semântico dessa sintaxe da enunciação, isto é, não só pelos indicadores de subjetividade, mas no e pelo recurso à língua toda. A experiência humana, então, não é anterior à linguagem. É na e pela linguagem que ela se instaura, em condições enunciativas que são sempre particulares.

O chamado quadro figurativo da enunciação, constituído pelo par eu-tu, conta com um terceiro elemento, o ele, em geral, remetido ao âmbito não-subjetivo da língua. Ora, se a tomada de palavra dá existência a eu-tu, instaurando a instância de discurso, é na e pela enunciação que o "mundo" passa a existir. Assim, a "objetividade” da não-pessoa se desfaz no momento em que ela é atualizada em uma situação enunciativa (FLORES et al., 2008, p. 62-64). Nesse sentido, o dizer, não importando o que se diga, está submetido à enunciação, isto é, está impregnado pela presença de eu-tu-aqui-agora.

O par eu-tu diz das figuras que, na posição de parceiros, são alternativamente protagonistas da enunciação. Já o ele não se reduz ao "falado", ao "tema" do discurso. Para melhor compreender essa questão, recorro à leitura das formulações de Benveniste sobre os pronomes feita pelo filósofo D-R. Dufour (2000). Essa leitura mostra que a integração do ele ao quadro figurativo insere a questão da ausência na enunciação, pois ele designa o que não está aqui e agora quando eu e tu falam. ${ }^{14}$ Sendo aquele que não está, ele se refere a uma ausência, que tanto pode ser: uma ausência re-presentada no campo da presença (2000, p. 107), isto é, aquilo que se pode chamar de "tema”/“objeto” do discurso diretamente nomeado; uma ausência não-nomeada, ideias e concepções não expressas, crucialmente implicadas na interlocução (aquilo que fala em mim quando falo); e até mesmo uma ausência da ordem do irrepresentável ${ }^{15}$, dizendo respeito ao que, embora anterior e exterior ao sujeito, o determina.

Assim, pode-se entender o ele como tendo um duplo estatuto: é o falado e, nesse sentido, é coconstruído na relação intersubjetiva $e u$-tu; é o que fala em $e u$-tu, isto é, a alteridade que intervém crucialmente no dizer de $e u$-tu, tanto como um terceiro que, embora não-dito, é da ordem do articulável, quanto como um lugar terceiro que escapa à consciência e, portanto, resiste à nomeação ${ }^{16}$ (TEIXEIRA, 2012b).

Admitir a instanciação de um terceiro elemento, ausente do discurso, faz da enunciação o lugar de uma relação que implica eu-tu/ele. É por essa configuração trinitária que se vai procurar dar visibilidade ao que acontece no processo de instauração de profissionais de enfermagem na atividade de trabalho.

As noções da ergologia a que este trabalho recorre são apresentadas a seguir.

\footnotetext{
${ }^{14}$ A esse respeito, consultar Silva (2009).

${ }^{15}$ Esse sentido é grafado por Dufour como um ele barrado, e pode ser aproximado do que Lacan define como Outro. Para Lacan (1990, p. 198), o sujeito se constitui no campo do Outro, isto é, ele depende do significante e o significante está primeiro no campo do Outro. Em suas palavras, "O outro é o lugar em que se situa a cadeia do significante que comanda tudo que vai poder presentificar-se do sujeito, é o campo desse vivo onde o sujeito tem que aparecer” (1990, p. 193-194), entendendo-se a relação do sujeito ao Outro como engendrada por inteiro num processo de hiância (1990, p.196).

${ }^{16}$ O reconhecimento da intervenção desse "ele” não articulável na constituição do sentido não nos autoriza, como linguistas, a qualquer tentativa de “acessá-lo”. No entanto, é importante levar em consideração essa intervenção do não-nomeável para que não se caia na armadilha de reduzir o sentido ao registro do dizível.
} 


\section{A atividade e os usos de si}

O conceito de atividade é a espinha dorsal da ergologia. A partir dele, é possível ir ao encontro do trabalho sem neutralizar o "emaranhado de arbitragens" que o constitui, e que escapa a qualquer tentativa de enquadramento (SCHWARTZ, 2011, p. 146).

Na perspectiva ergológica, a atividade de trabalho é entendida como atravessada por um debate entre normas antecedentes reguladoras do fazer e a tendência a renormalização inerente aos humanos (SCHWARTZ, 2010, p. 198), que inclui um universo de valores, difíceis de serem dimensionados, implicando crucialmente o sujeito. "A actividade é um impulso de vida, de saúde, sem limite predefinido, que sintetiza, cruza e liga tudo o que se representa separadamente (corpo / espírito; privado / profissional; imposto / desejado, etc. ...)” (DURRIVE; SCHWARTZ , 2008, p. 23).

Os estudiosos do trabalho, sob esse viés, consideram que as normas que antecipam o agir social são obrigatoriamente refeitas/repensadas, por duas razões: de um lado, porque é impossível antecipar exaustivamente as normas antecedentes e, de outro lado, porque ser totalmente determinado por normas é invivível. A atividade de trabalho é, assim, um encontro indefinidamente refeito, que não ocorre sem uma tensão, isto é, sem uma dramática de usos de si.

O conceito de "uso de si" chama a atenção para a complexidade do humano. Há um uso de si pelo(s) outro(s), isto é, pelo já-dado nas instâncias que antecipam a atividade. E há um uso de si por si mesmo, que diz respeito à convocação de um "indivíduo singular com capacidades bem mais amplas do que as enumeradas pela tarefa" (DURRIVE; SCHWARTZ , 2008, p. 27).

Esse modo de ver o trabalho afasta a ideia de que o exercício profissional seja pura aplicação por uns de normas previamente pensadas por outros, pois o que temos aí é a configuração de um ato que convoca um indivíduo singular com capacidades incessantemente reconfiguradas pelo vivido aqui-e-agora. Assim, o exercício profissional é um lugar de microescolhas, que traz permanentemente à luz o que não é padronizável nas situações de trabalho.

A tentativa de tentar surpreender, na linguagem, a tensão entre normas antecedentes e renormalizações, pela qual se instaura a experiência humana no trabalho, traz a necessidade de compreender melhor as noções de norma e renormalização, propostas por Schwartz (2000).

Segundo o filósofo (2000), as normas que antecedem toda situação de trabalho são de grande complexidade, constituindo-se em fontes de prescrições contraditórias entre si:

- prescrições oficiais da organização do trabalho; conjunto pronto de especificações (manuais, programas...) para que se constitua a atividade do trabalho, normas antecedentes explícitas, formuladas à revelia do trabalhador;

- regras menos formais elaboradas no curso da história dos coletivos de trabalho, que nos parecem constituir uma espécie de “cultura” da empresa/instituição, não expressas, mas conhecidas, porque constituídas com a participação dos trabalhadores, no curso da atividade;

- normas do próprio trabalhador, traços de sua história pessoal, de sua experiência, não expressas e até mesmo obscuras para o próprio trabalhador.

No retrabalho que se dá na atividade, normas de diferentes graus de explicitação vão se colocar no debate, porque o outro (lugar de onde elas emanam) que aí está implicado tem diferentes estatutos. Trata-se de (a) um outro específico sobre o qual temos algum grau de conhecimento; (b) um outro ampliado, que abrange as normas criadas, ao 
longo do tempo, pela experiência de sujeitos vivendo em coletividade, não expressas, mas conhecidas por todos; (c) um outro mais abstrato, espécie de imaginário social por onde circulam as ideias e concepções que se relacionam ao modo de viver em uma comunidade; conjunto de sentidos que circulam entre os membros de uma coletividade; (d) um Outro, tal como formulado por Lacan, que é anterior e exterior ao sujeito, a partir do qual a vida psíquica é ordenada (TEIXEIRA, 2010).

Passo agora a apresentar a operacionalização do diálogo interdisciplinar aqui proposto na análise de recortes retirados de interlocuções entre profissionais de enfermagem em passagens de plantão. Meu objetivo é somente ilustrar que essa implicação teórica constitui-se como um lugar epistemológico produtivo a partir do qual olhar para o sujeito em atividade de trabalho, sob o pressuposto de que aspectos subjetivos são aí inevitavelmente mobilizados.

\section{A instauração da experiência de trabalho de profissionais de enfermagem em passagens de plantão}

Para fugir de discursos sobre o trabalho, construídos de um ponto de vista exterior à atividade, os estudos ergológicos tomam por objeto de investigação a atividade dos profissionais no seu acontecer, entendendo-a não como uma realidade-em-si, mas como uma realidade mediada pela linguagem.

A atividade de trabalho observada é a de profissionais de enfermagem de um hospital do interior do Rio Grande do Sul. ${ }^{17}$ Os dois recortes que serão analisados foram retirados de um corpus constituído por interlocuções entre as próprias profissionais ${ }^{18}$, em quatro passagens de plantão, que foram filmadas. Meu propósito aqui é restrito: mostrar, a partir da análise da tríade enunciativa, o que está implicado na instauração da experiência profissional nessa situação específica de trabalho.

A passagem de plantão requer que o profissional de enfermagem que deixa o turno de trabalho refira o mais claramente possível, e de forma objetiva, a situação dos pacientes que estiveram sob seus cuidados e os procedimentos realizados durante o plantão. No hospital em que a pesquisa foi realizada, a passagem é feita em dois momentos, envolvendo duas equipes (uma que entra e outra que sai), cada uma delas constituída por uma enfermeira e seis técnicas de enfermagem. Em cada momento, uma enfermeira passa o plantão a outra enfermeira; as técnicas em enfermagem assistem; raramente intervêm. $\mathrm{O}$ plantão observado foi o das $12 \mathrm{~h} 45 \mathrm{~min}$; o tempo de duração em média, por etapa, é de quinze minutos.

As passagens de plantão observadas não são orientadas por um conjunto de regras fixas claramente determinadas pelo hospital. A própria chefia admitiu, em entrevista concedida aos pesquisadores, que esses momentos não têm como assumir uma forma padronizada, tendo em vista a natureza do trabalho na área da saúde, sempre entremeado por acontecimentos imprevistos.

Embora não sejam regidas por prescrições explícitas, nas passagens de plantão, como em qualquer atividade de trabalho, de acordo com a ergologia, o profissional, além da pressão de normas instituídas fora da situação, está submetido a uma ausência (uso de si pelo outro), com as quais negocia, na situação, podendo questioná-las, transgredi-las e mesmo subvertê-las (uso de si por si).

\footnotetext{
17 Por acordo de confidencialidade feito com a coordenação e os profissionais de enfermagem que participaram da pesquisa, não será feito nenhum tipo de descrição do hospital para não correr o risco de que ele seja identificado.

${ }^{18}$ A equipe que participou da pesquisa era constituída inteiramente por profissionais do sexo feminino.
} 
A pergunta que norteia a análise é: o que acontece no processo de instituição da experiência de trabalho de profissionais de enfermagem em passagens de plantão?

Segundo a leitura de Benveniste que orienta este estudo, a trindade é constitutiva da enunciação. No corpus em análise, uma profissional de enfermagem se institui como eu para passar o plantão a outra equipe $(t u)$. Em todas as passagens, ocorre um diálogo do locutor com seu alocutário, que presentificam o ele (a situação do paciente). Nesse processo, um complexo de normas antecedentes está sempre atravessado. Assim, considerando-se a instanciação de um terceiro elemento na relação eu-tu que se institui na passagem de plantão, a ausência está sempre colocada, seja uma ausência presentificada pela nomeação (o paciente de quem se fala), seja uma ausência não diretamente expressa cuja "presença" regula de um outro lugar o fazer desses profissionais (as normas antecedentes). Pode-se dizer, então, que entre eu e tu se interpõe uma gama de ele(s), nem sempre delimitáveis, com os quais se opera um debate. É por essa relação eu-tu/ele que se busca dar visibilidade à instauração da experiência de profissionais de enfermagem nessa situação específica de enunciação.

Embora ciente de que não se pode explicar inteiramente o funcionamento humano, constituído que é por uma "matéria estranha", entrar na atividade de trabalho de enfermagem permite observar, em situação, as arbitragens, os debates de normas e valores dessas profissionais, ou seja, o modo como se instaura sua experiência de trabalho.

É necessário dizer, antes da apresentação da análise, que não se vai traçar uma espécie de "imagem” das enfermeiras a partir de seu discurso. A intervenção da concepção enunciativa de sujeito, nessa convergência disciplinar, não permite tomá-lo pelo que ele diz, isto é, de considerar que as formas linguísticas têm a propriedade de atribuir a ele um lugar estável, linguisticamente descritível, claramente delimitado no discurso. A subjetividade de que fala Benveniste coexiste com a enunciação, emergindo em cada ato de “apropriação” da língua pelo locutor.

A título de ilustração, como já dito, apresento a seguir uma breve análise de dois recortes, em que é feita a tentativa de apreender, na e pela enunciação, "as dramáticas de uso de si”, buscando tornar visível a tensão entre o "uso de si por si” e o "uso de si pelos outros”, isto é, o debate de normas, pelo qual se instaura esta experiência de trabalho.

\section{Recorte 1}

Passagem de plantão $\mathbf{n}^{0} 3$

Contexto enunciativo: As duas enfermeiras estão sentadas em torno da mesa, em que se encontram os prontuários. As auxiliares de enfermagem circulam pela sala. Nesse turno, houve uma parada cardíaca, o que agitou os funcionários.

Enfermeira Márcia ${ }^{19}$ : A Simone, ela teve uma dor toráxica súbita, ta, então (.) eles tão fazendo exames, fazendo talvez uma $\mathrm{DCP}^{20}$ ali, que eles iniciaram com a nebulização. A última nebulização deu taquicardia e tremores. Depois aliviou, ((Faz movimentos com as mãos, demonstrando que algo terminou)) AGORA HÁ POUCO, tá. Então tu tenta ver na próxima nebulização se dá alguma reação, ou então nós vamos ter que retirar, né. Só [tu] observa daí, mas no mais [ela] se manteve calma, tranquila, comunicativa. ${ }^{21}$

\footnotetext{
${ }^{19}$ Todos os nomes são fictícios.

${ }^{20}$ Doença Congestiva Pulmonar.

${ }^{21}$ Convenções de trascrição:

(.): um ponto entre parênteses indica que há uma pausa curta intra ou interturnos.

(...): três pontos entre parênteses indicam que há uma pausa longa intra ou interturnos.

PALAVRA em letra maiúscula: indica fala com intensidade acima da fala que a rodeia.

Palavra- hífen: indica corte abrupto da fala.
}

( ) parênteses vazios: indicam que o transcritor foi incapaz de transcrever o que foi dito - segmento ininterpretável.

(( )) parênteses duplos: indicam comentários do transcritor. 
No recorte 1, a enfermeira Márcia, que passa o plantão, se apropria da língua, instituindo-se como locutor (eu) diante de uma colega (tu) para falar de uma ausente nomeada, a paciente Simone (ela). Nessa interlocução, uma ausência não nomeada é introduzida pelo pronome eles (eles iniciaram com a nebulização ${ }^{22}$ ), cuja referência é ambígua: tanto pode ser a equipe de enfermagem encarregada de aplicar a nebulização, quanto a equipe médica responsável pela indicação desse fármaco.

Em seguida, a enfermeira Márcia faz o relato de uma intercorrência: a nebulização provocou taquicardia e tremores na paciente. Seu empenho é enfatizar para a colega que assume o turno de trabalho a necessidade de uma atenção especial a essa paciente no momento da próxima aplicação do medicamento.

Destaca-se de modo especial, neste recorte, o uso particular da forma pronominal nós, feito pela enfermeira Márcia. Essa forma está entre os indicadores de subjetividade, que, segundo Benveniste, são disponibilizados pela língua para instanciar o locutor em seu discurso. Tradicionalmente, é descrita como primeira pessoa do plural. Benveniste (PLG I, p. 256), no entanto, contraria essa descrição, chamando a atenção para o fato de que os pronomes não se colocam dentro "dos processos ordinários de pluralização". No caso específico de nós, o autor esclarece que "a unicidade e a subjetividade inerentes a eu contradizem a possibilidade de uma pluralização". Em nós, eu faz conjunto com não-eu: $e u+t u$ ou $e u+e l e(s)$ ou ainda $e u+t u+e l e(s)$. Estamos diante de uma pessoa ampliada por "uma globalidade indistinta de outras pessoas" (BENVENISTE, PLG I, p. 258), em que o eu está sempre presente. ${ }^{23}$

Observe-se que, nesse recorte, a enfermeira Márcia está deixando o plantão, portanto, não estará presente na próxima nebulização da paciente. Ela solicita que a colega (explicitamente nomeada como tu) preste especial atenção a essa paciente, que apresentou taquicardia e tremores durante o procedimento de nebulização. Se reações adversas forem constatadas, um conjunto indistinto de outras pessoas, referidas pelo pronome nós, terá que agir para interromper o processo.

Na busca de referente para esse nós, somos tentados a concluir que seja a equipe que assume o turno de trabalho, já que Márcia (eu) está deixando o plantão. Nesse caso, estaríamos diante de um uso de nós equivalente a vocês, ou seja, a primeira pessoa do plural estaria assumindo aí o sentido de segunda pessoa do plural. Interpretado dessa forma, esse nós, por não ter o eu como um de seus referentes, poderia se enquadrar no que Fiorin $^{24}$ (1996, p. 93) chama de "uso subvertido" dos pronomes.

No entanto, se olharmos para esse recorte sob a perspectiva da ergologia, a interpretação de que esse uso de nós não inclui o eu não se sustenta. No trabalho em hospitais, o setor de enfermagem é que observa cotidianamente o estado do doente. Sua função é colocar em dialética o conhecimento geral que o profissional deve ter sobre o cuidado do doente e a forma como cada um dos que estão sob cuidado reage no aqui-eagora. Trata-se de trabalho que envolve vários elementos e/ou aspectos distintos, que requer um conjunto de conhecimentos, habilidades e atitudes, em que valores são sempre colocados à prova. A segurança do doente está no centro dessa atividade. Nesse sentido, a identificação de situações de risco e a antecipação de recursos capazes de prevenir essas situações adversas são determinantes para garantir a qualidade do cuidado.

\footnotetext{
${ }^{22}$ Procedimento realizado conforme prescrição médica para favorecer o processo de fluidificação de secreções respiratórias do cliente e/ou aumentar a oferta de $\mathrm{O}^{2}$, através de um método não invasivo. (Cf. http://enfermagemcontinuada.blogspot.com.br/2011/02/e-o-procedimento-realizado-conforme.html. Acesso em dez. 2012).

${ }^{23}$ No caso do nós de majestade e do nós de autor ou de orador, o eu predomina.

${ }^{24}$ Segundo Fiorin (1996), há casos em que os pronomes aparecem "subvertidos", assumindo sentidos que se desviam da interpretação usual que deles é feita.
} 
O nós com aparente valor de vocês, nessa situação específica de enunciação, faz emergir um sujeito que acredita no trabalhar com os outros, que está em sinergia com o meio de trabalho, vivido como sendo seu. Materializa-se aí a mobilização de um engajamento com a equipe de enfermagem que atua no hospital, de um envolvimento particular com a paciente Simone, de uma responsabilização sobre ela que não cessa no final do plantão. A enfermeira que está saindo viveu a intercorrência com a paciente no momento da nebulização, estando impregnada dessa dimensão histórica, enquanto as colegas que estão entrando não experienciaram essa situação adversa, que chega a elas apenas pelo relato.

A afirmação que C. L. C. Silva faz, com apoio em Benveniste, contribui para a compreensão do aspecto que está em análise: “A língua como atividade discursiva é dependente da experiência de cada locutor, ligada às relações intersubjetivas e às instituições sociais em que está inscrito” (SILVA, 2009, p. 189).

A instanciação como nós, no recorte em estudo, ilustra a questão central que a ergologia traz à discussão: na atividade de trabalho, cada um é "convocado numa dimensão singular, histórica, não estandardizável” (DURRIVE; SCHWARTZ, 2008, p. 27). Cada um significa de forma própria o que vive, apresenta graus diversos de envolvimento com a situação. Desse modo, a experiência de trabalho mobiliza funcionamentos subjetivos de tal forma complexos que não se consegue alcançá-los em toda sua extensão.

Recorte 2

Passagem de plantão $\mathrm{n}^{0} 1$

Contexto Enunciativo: As duas enfermeiras estão sentadas em torno da mesa, em que se encontram os prontuários. As auxiliares de enfermagem circulam pela sala.

Enfermeira Teresa: 19 é dona Rute. E [eles/elas] tão aguardando pela Tati pra ( ) só que [eles/elas] não prescrevem nada. Ela também disse que só tem náuseas de manhã cedo, tá tudo bem.

Como já dito, em passagens de plantão, eu (enfermeira que sai) se apropria da língua e dirige-se a tu (enfermeira que assume o turno) para falar de ele (paciente). De acordo com a perspectiva deste trabalho, nessa interlocução, instâncias ausentes se interpõem, configurando a "presença" do uso de si pelo outro.

No recorte 2, a enfermeira Teresa, que passa o plantão, relata a queixa de náusea da paciente dona Rute, ficando implícito que nada foi ainda feito para resolver a situação, porque “[eles/elas] estão aguardando pela Tati”, a médica encarregada de prestar assistência à paciente. A situação pode ser assim resumida: dona Rute se queixa de náuseas, algo precisa ser feito, mas a equipe que está no plantão espera o aval da médica da paciente (Tati), que, no momento, não está no hospital.

Teresa faz uso de dois pronomes elípticos (eles ou elas), sem remetê-los a antecedentes anteriormente mencionados. A enfermeira que recebe o plantão não demonstra dificuldade em identificar os "indivíduos” indeterminados que são designados por eles (ou elas), pois não faz nenhuma intervenção no sentido de perguntar a Teresa a quem ela está se referindo. A identificação do referente é feita pelo conhecimento compartilhado por ambas em relação a essa situação.

Aos olhos do analista, a primeira ocorrência de eles (ou elas) elíptico tanto pode referir os auxiliares de enfermagem como os médicos que estão no plantão. $\mathrm{O}$ verbo "prescrevem”, em "só que [eles] não prescrevem nada”, no entanto, fornece a chave para a recuperação do referente de eles (ou elas) elíptico, sem antecedente: são os médicos que têm a atribuição de prescrever procedimentos na área da saúde. Assim, o pronome eles/elas refere-se à equipe médica. 
A expressão "só que”, comum na oralidade, que corresponde ao conector "mas", introduz uma crítica implícita à equipe médica, deixando entender que eles deveriam prescrever algum tipo de medicamento para aliviar o desconforto da paciente. É nítido que Teresa não legitima a situação tal como se apresenta, ela não deixa de expressar seu desacordo em relação ao que está acontecendo, mas imediatamente o atenua pelo recurso ao discurso citado, atribuído à paciente, acompanhado de um marcador de adição "também”: "Ela (dona Rute) também disse que só tem náuseas de manhã cedo, tá tudo bem”, parafraseável por “ela não tem náuseas o dia todo”. Ou seja: sua situação não é tão grave assim.

A tensão entre o uso de si por si e o uso de si pelo outro, mesmo que de forma sutil, pode ser observada. Teresa intervém na situação deixando ver sua desaprovação diante de uma possível “omissão” da instância médica em relação à administração de um medicamento para aliviar as náuseas de dona Rute. No último segmento, no entanto, talvez para se resguardar de um possível juízo negativo da parte de sua interlocutora, ela se vale de discurso atribuído a dona Rute, e ameniza a situação. Com isso, protege-se de ser vista como quem se arvora a questionar a hierarquia, que, nesse hospital, ainda é bastante centrada na equipe médica. Os valores de Teresa confrontam-se aqui com normas oriundas da cultura institucional.

O recorte 2 ilustra o jogo de presença/ausência, em que se pode perceber o que está implicado na instauração da experiência subjetiva na atividade de trabalho. O par eu-tu instancia as figuras que, pela inversibilidade, constituem-se alternadamente como protagonistas da enunciação. O ele insere uma dupla ausência: a paciente cuja situação é o tema da conversa levada a efeito neste momento da passagem de plantão, configurando-se como uma ausência nomeada; uma ausência não expressa, mas conhecida pelos interlocutores, com quem é instituída uma espécie de negociação sobre o encaminhamento de práticas de cuidado. Essa situação exemplifica o que diz Schwartz (2012): toda a atividade humana é um destino a viver e ninguém está isento de ter que arbitrar aí um debate de normas a partir de valores que lhe são próprios.

Apesar de ter realizado uma demonstração restrita do tipo de análise que o referencial teórico deste estudo permite, acredito que os exemplos trazidos indicam a potencialidade dessa linha de pesquisa, que oportuniza a realização de trabalho inovador, voltado à extensão da teoria de Benveniste para além da descrição de fatos de língua stricto sensu, que tem descortinado um universo complexo e, em muitos aspectos, inexplorado no campo da pesquisa em linguística aplicada.

Scherer, Pires e Schwartz (2009, p. 725) destacam que a ergologia "não negligencia as determinações e constrangimentos macropolíticos e econômicos", mas propõe que, "no exercício das atividades cotidianas", são os trabalhadores que fazem "a gestão de si mesmos e de sua relação com os outros participantes de coletivos de trabalho". Nesse sentido, microanálises como as aqui propostas revestem-se de importância, pois é na e pela linguagem que se materializam as interpretações do mundo, as negociações de valores, enfim, a instauração da experiência de trabalho. Essas microanálises, no entanto, não podem ser desconectadas da discussão de questões epistemológicas, à medida que se relacionam com modos não convencionais de produzir o conhecimento que seguem na direção de uma ciência que se conecte com a vida.

\section{REFERÊNCIAS}

AGAMBEN, G. Infância e história: destruição da experiência e origem da história. Trad. Henrique Burigo. Belo Horizonte: Editora UFMG, 2008. 
BARTHES, R. O rumor da língua. Trad. Mario Laranjeira. São Paulo: Editora Brasiliense, 1988. p. 30-39.

BENVENISTE, É. Problemas de linguística geral II. Trad. Eduardo Guimarães et al. Campinas, SP: Pontes, 1989.

BENVENISTE, É. Problemas de linguística geral I. Trad. Maria da Glória Novak e Maria Luiza Neri. Campinas, SP: Pontes, 1988.

CANGUILHEM, G. O normal e o patológico. 6.ed. Trad. Maria Thereza Redig de Carvalho Barrocas. Rio de Janeiro: Forense Universitária, 2007.

CASTRO, E. V. Os pronomes cosmológicos e o perspectivismo ameríndio. Mana 2(2): 115-144, 1996.

DESSONS, G. Émile Benveniste, l'invention du discours. Paris: Editions In Press, 2006.

DUFOUR, D-R. Os mistérios da trindade. Trad. Dulce Duque Estrada. Rio de Janeiro: Companhia de Freud, 2000.

DURRIVE, L.; SCHWARTZ, Y. Glossário da Ergologia. Laboreal, 4, (1), 23-28, 2008. http://laboreal.up.pt/revista/artigo.php?id=48u56oTV6582234396587; 63882. Trad. Liliana Cunha e Marianne Lacomblez.

FIORIN, J. L. As astúcias da enunciação. São Paulo: Ática, 1996.

FLORES, V. N. Sujet de l'énonciation et ébauche d'une réflexion sur la singularité énonciative. In: NORMAND, C.; SOFIA, E. (dir.). Espaces théoriques du langage: des parallèles floues. Louvain: L’Harmatann Academia S.A, Belgica, 2013, v. 1, p. 87-128.

FLORES, V. N. et al. Enunciação e gramática. São Paulo: Contexto, 2008.

JUCHEM, A. Por uma concepção da escrita e re-escrita de textos em sala de aula: os horizontes de um hífen. Dissertação de Mestrado. Porto Alegre: Programa de PósGraduação em Letras, UFRGS, 2012. Orientação: Profa. Dra. Carmem Luci da Costa Silva.

LACAN, J. O campo do outro e o retorno da transferência. In: O seminário, livro 11: os quatro conceitos fundamentais da psicanálise (1964). Trad. M.D. Magno. Texto estabelecido por Jacques-Alain Miller. Rio de Janeiro: Zahar, 1990. p. 191-245.

ONO, A. La notion d'énonciation chez Émile Benveniste. Limoges: Lambert-Lucas, 2007.

SANTOS, B. S. Um discurso sobre as ciências. 13.ed. Coimbra: Edições Afrontamento, 2002.

SCHERER, M. D. A.; PIRES, D.; SCHWARTZ, Y. Trabalho coletivo: um desafio para a gestão em saúde. Rev. Saúde Pública. 43 (4), 2009, p. 721-725.

SCHWARTZ, Y. Postface à l'édition de 2012. In : travail. Paris: Les Éditions Sociales, 2012. p. 923-943. Expérience et connaissance du

SCHWARTZ, Y. Conceituando o trabalho: o visível e o invisível. Trabalho, Educação, Saúde, Rio de Janeiro, v. 9, supl.1, p. 19-45, 2011.

SCHWARTZ, Y. O trabalho numa perspectiva filosófica. Trad. Marie-Annik Bernier. In: NOZAKI, I. (org.). Educação e trabalho: trabalhar, aprender, saber. São Paulo: Mercado de Letras, 2008. p. 23-46.

SCHWARTZ, Y. Le paradigme ergologique ou un métier de philosophe. Toulouse: OCTARES, 2000. 
SCHWARTZ, Y.; DURRIVE, L. (org.). Trabalho \& Ergologia: conversas sobre a atividade humana. Coord. Trad.: Jussara Brito e Milton Athayde. Niterói: Editora da UFF, 2010.

SILVA, C. L. C. A criança na linguagem: enunciação e aquisição. Campinas, SP: Pontes, 2009.

SOUZA-E-SILVA, M. C. P.; MOTTA, A. R. Le langage et le travail - Rapprochements entre l'approche ergologique et les études du langage. Anais do Premier Congrès de la Société Internationale d'Ergologie. Strasbourg, Fr., 2012.

TEIXEIRA, M. O estudo dos pronomes em Benveniste e o projeto de uma ciência geral do homem. Desenredo, Passo Fundo, v. 8, n. 1, p. 71-83, jan./jun. 2012a.

TEIXEIRA, M. “A linguagem serve para viver”: contribuição de Benveniste para análises no campo aplicado. Linguagem \& Ensino, Pelotas, v.15, n.2, p. 439-456, jul./dez. 2012b.

TEIXEIRA, M. Dimensão subjetiva da atividade de trabalho: um olhar multidisciplinar. Correio APPOA, março, 2010. p. 45-53.

Recebido em fevereiro de 2013.

Aprovado em abril de 2013. 